\title{
Manufacturing Mental Disorder by Pathologizing Erotic Age Orientation: A Comment on Blanchard et al. (2008)
}

\author{
Philip Tromovitch
}

Published online: 16 October 2008

(c) Springer Science+Business Media, LLC 2008

If I had been a peer-reviewer for the Blanchard et al. (2008) article, "Pedophilia, Hebephilia, and the DSM-V," with only minor revisions, I would have recommended publication. The article appears to provide a solid, basic science investigation of some of the categories of erotic age orientation. The bulk of this peer-reviewed article appears to be scientific and to contribute to the advancement of knowledge.

Regrettably, however, Blanchard et al. did not merely report on their research and draw appropriate conclusions. Instead, they recommended a potentially dramatic expansion or addition to the DSM diagnostic categories of mental disorders without any evidence or reasoning that those who would be newly included under the mental disorder rubric can be properly categorized as mentally disordered. Blanchard et al. did not define mental disorder. They did not measure mental disorder. They did not examine associations with mental disorder. They did not provide reasoning that leads to a conclusion of mental disorder. However, they did assert, without evidence or reasoning, that the DSM should be expanded to include more people as having a mental disorderand they did this in the most prominent "take home message" locations in their article-in the abstract and in the first paragraph of their discussion section-even the title alludes to the article's connection to DSM modification. In the first paragraph of the discussion section, Blanchard et al. wrote:

...the DSM-V should expand the definition of Pedophilia so that it includes erotic attraction to pubescent and prepubescent children or, alternatively, add a separate diagnosis of Hebephilia....Another possibility would be to completely replace the diagnosis of

P. Tromovitch $(\bowtie)$

College of Liberal Arts and Sciences, Tokyo Medical and Dental

University, 2-8-30 Konodai, Ichikawa, Chiba 272-0827, Japan

e-mail: tromovitch.las@tmd.ac.jp
Pedophilia with Pedohebephilia and allow the clinician to specify one of three subtypes...

Like masturbation and homosexuality, pedophilia (informally: erotic attraction to prepubescent people) appears to have entered the DSM as a "mental disorder" without any scientific or rational basis, perhaps because, like masturbation and homosexuality, pedophilia does not usually lead to procreation. Indeed, even today, there appears to be no rational scientific basis for the inclusion of pedophilia as a defined mental disorder (cf. Green, 2002; Moser \& Kleinplatz, 2005; Suppe, 1984). When appearing in an article that did not examine or discuss the concept of mental disorder, I find the Blanchard et al. (2008) call to expand the definition problematic.

The Archives and the authors should publish an errata clearly indicating that the Blanchard et al. (2008) article provided no evidence or reasoning to support their recommendation regarding the expansion of the problematic diagnostic category of pedophilia. The Archives should additionally examine its peer-review system to determine how such a prominent recommendation - that does not follow from the research reported in the article-was allowed to be published, and take steps to minimize this type of problem from reoccurring.

\section{References}

Blanchard, R., Lykins, A. D., Wherrett, D., Kuban, M. E., Cantor, J. M., Blak, T., et al. (2008). Pedophilia, hebephilia, and the DSM-V. Archives of Sexual Behavior. doi:10.1007/s10508-008-9399-9.

Green, R. (2002). Is pedophilia a mental disorder? Archives of Sexual Behavior, 31, 467-471.

Moser, C., \& Kleinplatz, P. J. (2005). DSM-IV-TR and the paraphilias: An argument for removal. Journal of Psychology and Human Sexuality, 17(3/4), 91-109.

Suppe, F. (1984). Classifying sexual disorders: The Diagnostic and Statistical Manual of the American Psychiatric Association. Journal of Homosexuality, 9, 9-28. 